\title{
1. Introduction to Polar Law
}

\author{
Karen N Scott and David L VanderZwaag
}

This Chapter sets the course for navigating the following 21 chapters authored by leading researchers in the field of Polar Law. The contributors to this volume seek to capture the status and future directions for research relating to the many components of law and policy relating to the Antarctic and Arctic regions. Those components include the array of regional agreements and arrangements of application to the Poles; the management of specific human Polar activities (fishing, shipping, tourism, bioprospecting and non-living resource exploitation); the promotion of scientific cooperation; the resolution of competing jurisdictional claims and ocean boundary disputes; the recognition of Indigenous and human rights; the prevention and control of pollution; the conservation of marine mammals; the establishment of marine protected area networks; and the commitments to mitigate and adapt to climate change and ocean acidification.

This introductory Chapter identifies the key questions that frame the fast-changing arena of Polar Law and which set the tone and parameters of this Research Handbook. The most fundamental question is "what is "Polar Law"'? In attempting to answer this question, we engage with the issue of how to define and describe the Poles before going on to articulate two possible definitions of Polar Law. In developing the first definition, we ask whether we can readily and clearly identify a set of rules and principles that apply to the Polar regions. In articulating a second, more challenging definition, we ask whether it is possible to identify a body of rules and principles that apply coherently across both Poles based on common values. Given the acknowledged challenges of this exercise, we go on to briefly ask whether we need Polar - rather than Arctic and Antarctic - law and draw some preliminary conclusions as to the benefits of a Polar rather than a bipolar approach. Finally, we examine a selection of the challenges to Polar Law, a theme which is taken up in detail by all authors in this Research Handbook across the various areas identified above.

\section{WHAT IS 'POLAR LAW'?}

The Arctic and the Antarctic, or the 'Poles', have been linked in legal literature for over 100 years ${ }^{1}$ with proposals for Polar demilitarization or even internationalization having a lineage of at least 60 years. ${ }^{2}$ The presence of ice has provided authors with an opportunity to explore the application of a common regime to both Poles, ${ }^{3}$ and the privileged role the law of the sea

\footnotetext{
See Thomas Willing Balch, 'The Arctic and Antarctic Regions and the Law of Nations' (1910) 4 American Journal of International Law 265.

2 See Robert D Hayton, 'Polar Problems and International Law' (1958) 52 American Journal of International Law 746, 764.

3 See Christopher C Joyner, 'Ice-Covered Regions in International Law' (1991) 31 Natural Resources Journal 213.
} 
plays in both regions has led to various studies on Polar marine law. ${ }^{4}$ More recently however, the term 'Polar Law' has entered the lexicon of international legal scholarship ${ }^{5}$ and it is this concept that is explored in this Research Handbook.

What is 'Polar Law'? Is it nomenclature that describes the collective of rules, principles and soft obligations that, in the words of Rothwell and Hemmings in Chapter 22 of this volume, 'distinctively applies to the Polar regions, in much the same way that there is considered to be a separate and distinctive body of law that applies to outer space'? This approach to 'Polar Law' is adopted by Natalia Loukacheva in the introduction to the Polar Law Textbook, where Polar Law is defined as general international law applicable to the Arctic and the Antarctic, international law that deals with issues specific to the Polar regions, and applicable domestic law. ${ }^{6}$ As demonstrated by each of the contributors to this Research Handbook, there are separate and distinctive rules that apply to both the Arctic and the Antarctic with respect to governance, exploitation of resources, scientific research, conservation and many other areas. In areas such as shipping and the application of environmental principles, including precaution, there is significant synergy across both Poles.

However, this Research Handbook also asks whether 'Polar Law' goes beyond nomenclature to constitute an internally coherent body of law based on an identifiable set of values and principles such that we can predict how future 'Polar Law' might develop based on these principles and values. The idea of distinct principles developed for the Poles - sometimes referred to as 'Polar exceptionalism' and Hemmings in Chapter 22 describe the adaptation — or relaxation — of international rules relating to occupation of territory to take account of harsh Polar conditions ${ }^{8}$ and the development of the sector principle in order to justify a claim over an unoccupied area on the basis of (typically) coastal Polar occupation. ${ }^{9}$ Moreover, Polar regional governance mechanisms are also distinctive in that they have deliberately adopted an international or quasi-international outlook, acknowledging the interest of the broader international community in the Polar

4 See, e.g., Davor Vidas, Protecting the Polar Marine Environment: Law and Policy for Pollution Prevention (Cambridge: Cambridge University Press, 2000); Alex G Oude Elferink and Donald R Rothwell (eds), The Law of the Sea and Polar Maritime Delimitation and Jurisdiction (Martinus Nijhoff Publishers, The Hague, 2001); Alex G Oude Elferink, Erik J Molenaar and Donald R Rothwell, The Law of the Sea and Polar Regions: Interaction between Global and Regional Regimes (Martinus Nijhoff, Leiden, 2013); Tim Stephens and David L VanderZwaag (eds), Polar Oceans Governance in an Era of Environmental Change (Edward Elgar, Cheltenham, 2014); Nengye Liu, Cassandra M Brooks and Tianbao Qin (eds), Governing Marine Living Resources in the Polar Regions (Edward Elgar, Cheltenham, 2019).

$5 \quad$ See Loukacheva (ed), Polar Law Textbook (TemaNord, Copenhagen, 2010); Donald R Rothwell and Alan D Hemmings (eds), International Polar Law (Edward Elgar, Cheltenham, 2018). In 2009 the Yearbook of Polar Law was established. See also Dawid Bunikowski and Alan D Hemmings (eds), Philosophies of Polar Law (Routledge, forthcoming 2020).

6 Loukacheva, ibid, 13.

7 For a discussion of 'Antarctic exceptionalism' see Alan D Hemmings, 'From the New Geopolitics of Resources to Nanotechnology: Emerging Challenges of Globalism in Antarctica' (2009) 1 The Yearbook of Polar Law 55.

$8 \quad$ Legal Status of Eastern Greenland (Norway v. Denmark) (1933) PCIJ Reports, Ser. A/B No. 53.

9 See Charles Cheney Hyde, ‘Acquisition of Sovereignty over Polar Areas' (1933-1934) 19 Iowa Law Review 286. 
regions. The 1920 Treaty of Spitzbergen ${ }^{10}$ led the way in developing Arctic governance based on a non-traditional form of territorial sovereignty, and the 1959 Antarctic Treaty ${ }^{11}$ transcended - without entirely abandoning — state sovereignty, creating the first de facto internationalized space. The Arctic is of course largely subject to traditional sovereign control but, at the regional level, the Arctic Council, established in 1996, provides for the participation of six Indigenous groups as 'Permanent Participants' in order to provide for their 'active participation and full consultation' as well as non-Arctic observer states and international organizations, ${ }^{12}$ although decisions are taken by member state consensus. ${ }^{13}$ Klaus Dodds has described the Antarctic as a location 'for experimentation in human governance' ${ }^{14}$ and this description is equally apt when applied to the Arctic.

Distinctive values and principles that underpin the regional regimes at both Poles can easily be identified. The Antarctic Treaty System, which Jill Barrett describes in Chapter 3 of this volume as 'more than a collection of treaties and rules', is based on the fundamental principles of peaceful purposes, freedom of scientific research, cooperation and transparency of operation, and strict environmental protection. In the Arctic, the regional regime is 'emerging', but is clearly founded on the principles of peaceful cooperation, scientific research and precautionary environmental management according to Timo Koivurova, Pirjo Kleemola-Juntunen and Stefan Kirchner in Chapter 4 of this Research Handbook. Erik Molenaar's 2012 thesis that an 'Arctic Council System' is developing ${ }^{15}$ has only strengthened over the last decade with the adoption of three binding instruments under the auspices of the Council (on search and rescue (2011), oil preparedness and response (2013) and scientific cooperation (2017)). The 'System' is further developed by the adoption of institutionally distinct but mutually supportive Arctic measures such as the 2018 Agreement to Prevent Unregulated High Seas Fisheries in the Central Arctic Ocean (CAOFA), ${ }^{16}$ discussed in detail by Alf Håkon Hoel in Chapter 11 of this volume. But a key question for this Research Handbook is whether we can identify Polar principles and values; that is, principles and values that apply across the Arctic and the Antarctic and can be said to underpin Polar Law as a discrete and internally coherent body of law.

10 Treaty concerning the Archipelago of Spitsbergen, adopted 9 February 1920, entered into force 14 August 1925, 2 LNTS 8.

11 Antarctic Treaty, adopted 1 December 1959, entered into force 23 June 1961, 402 UNTS 71.

12 Currently there are 13 observer states (France, Germany, Italy, Japan, The Netherlands, China, Poland, India, Korea, Singapore, Spain, Switzerland and the United Kingdom) in addition to 13 intergovernmental organizations and 12 non-governmental organizations, which are also observers. Arctic Council, 'Who is the Arctic Council?' at https://arctic-council.org/en/ (accessed 7 April 2020).

13 Declaration on the Establishment of the Arctic Council, 19 September 1996 [Ottawa Declaration], at https://oaarchive.arctic-council.org/handle/11374/85 (accessed 23 April 2020), para 2.

${ }_{14}$ Klaus Dodds, 'The Antarctic Treaty, territorial claims and a continent for science' in Mark Nuttal, Torben R Christensen and Martin Siegert (eds), The Routledge Handbook of the Polar Regions (Routledge, London, 2018) 265, 265.

15 EJ Molenaar, 'Current and Prospective Roles of an Arctic Council System within the Content of the Law of the Sea' (2012) 27 International Journal of Marine and Coastal Law 553.

16 Agreement to Prevent Unregulated High Seas Fisheries in the Central Arctic Ocean, adopted 3 October 2018, not yet in force, OJ L 73/3 (15 March 2019) [CAOFA]. 


\section{HOW ARE THE 'POLES' DEFINED AND DESCRIBED?}

Before attempting to define 'Polar Law' it is necessary to define the 'Poles' or the regions to which this body of law applies.

In the case of the Antarctic this exercise is relatively straightforward. Article VI of the Antarctic Treaty defines the scope of the Treaty as applying to the area south of 60 degrees south latitude, including all ice shelves (Map 1.1 below). Although Article VI of the Treaty includes a without prejudice clause in respect of high seas freedoms, the Antarctic Treaty System (ATS) has evolved over the years to regulate and manage a range of activities taking place in the marine environment, including scientific research, exploitation of living and non-living resources, tourism and even shipping. The scope of the 1991 Environmental Protocol to the 1959 Antarctic Treaty (Madrid Protocol) ${ }^{17}$ is coterminous with that of the Treaty, and the reference to 'dependent and associated ecosystems' in Article 2 of the Protocol has not been used in practice as a basis to expand its regulatory reach. The 'Antarctic Treaty area' has also been adopted within international instruments with special application to the Antarctic. For example, with regards to shipping, the Antarctic Special Areas under Annexes I, II and V of 1973/78 MARPOL ${ }^{18}$ coincide with the Antarctic Treaty area (south of 60 degrees south latitude) and the application of the Polar Code ${ }^{19}$ is similarly constrained in scope to the Antarctic Treaty area. The scope of the ATS is broadened in respect of fisheries management by the 1980 Convention on the Conservation of Antarctic Marine Living Resources (CAMLR Convention), ${ }^{20}$ which applies to the entire Antarctic ecosystem, defined geographically to include the area up to the Antarctic Convergence (a natural barrier where warmer northern waters meet cooler southern waters) in addition to the area south of 60 degrees south latitude. ${ }^{21}$

By contrast, there is no one definition of the Arctic (Map 1.2 below). ${ }^{22}$ A commonly used definition is the region above the Arctic Circle, an imaginary line circling the globe at approximately $66^{\circ} 34^{\prime} \mathrm{N} .^{23}$ That latitude marks the line above which the sun does not set on the summer solstice and does not rise on the winter solstice. ${ }^{24}$ Other definitions include the area north of the Arctic treeline and locations in high latitudes where the average daily summer temperature

17 Protocol on Environmental Protection to the 1959 Antarctic Treaty, adopted 4 October 1991, entered into force 14 January 1998, 2941 UNTS 3 [Madrid Protocol].

18 International Convention for the Prevention of Pollution from Ships, adopted 17 February 1973, entered into force 2 October 1983, as amended by the Protocol of 1978 (MARPOL 73/78), adopted 17 February 1978, entered into force 2 October 1983, 1340 UNTS 61.

19 International Code of Safety for Ships Operating in Polar Waters (Polar Code), IMO Resolution MSC.385(94), 21 November 2014, and IMO Resolution MEPC.264, 15 May 2015, both effective 1 January 2017; Amendments to the International Convention for the Safety of Life at Sea 1974 (SOLAS), IMO Resolution MSC.386(94), 21 November 2014, effective 1 January 2017; Amendments to MARPOL Annexes I, II, IV and V, IMO Resolution MEPC.265(68), 15 May 2015, effective 1 January 2017.

20 Convention on the Conservation of Antarctic Marine Living Resources, adopted 20 May 1980, entered into force 7 April 1982, 1329 UNTS 48.

21 Ibid, Art I.

22 See Lorne Kriwoken, 'Environmental change in the Arctic' in Stephens and VanderZwaag, note 4, $42,44-45$.

${ }_{23}$ National Snow and Ice Data Center, 'What is the Arctic?' at https://nsidc.org/cryosphere/arctic -meteorology/arctic.html (accessed 14 April 2020).

24 Ibid. 
does not arise above 10 degrees Celsius. ${ }^{25}$ The Arctic Council's working groups have adopted differing definitions that reflect their particular interests. ${ }^{26}$ For example, the Arctic Monitoring and Assessment Programme (AMAP) Working Group has adopted a compromise among the various definitions incorporating elements of the Arctic Circle, political and vegetation boundaries, permafrost limits and major oceanographic features. ${ }^{27}$ Meanwhile, the Conservation of Arctic Flora and Fauna (CAFF) Working Group has largely followed the treeline in order to include ecosystems of concern. ${ }^{28}$ The Polar Code defines Arctic waters by a complicated setting out of geographical positions between Cap Kanin Nos (Russian Federation) and a point off the southern tip of Greenland, completed by the circle formed at latitude 60 degrees north and relevant coast lines. ${ }^{29}$

Despite the dominating presence of ice at both Poles, there are significant geological, anthropological, economic and regulatory differences between the two regions. It is trite, but nevertheless true, that Antarctica is a continent surrounded by ocean whereas the Arctic is an ocean surrounded by continents. This distinction has become more profound in the last 50 years as Arctic sea ice has given way to open ocean as far as the North Pole for increasing parts of each year. Of arguably greater significance, the Arctic is the home to Indigenous peoples whereas the Antarctic hosts only transient populations of tourists and scientists. This fundamentally affects how human rights and the law which applies to 'peoples at the poles' is implemented within both regions, a theme explored by Sara Seck and Sarah MacLeod in Chapter 5 of this volume. They ask 'does the "people" element represent an insurmountable difference in terms of Polar Law?' The presence of people has also led to very different approaches to the exploitation of Polar resources, particularly mineral resources. The Arctic approach of managed exploitation in contrast to the ban on commercial minerals activities in the Antarctic is explored by Rachael Johnstone and Scott Joblin in Chapter 13 of this Research Handbook. The differences in attitudes to minerals exploitation is in part a consequence of the different sovereign and regulatory status of the Poles. The Arctic, as noted above, is largely subject to the sovereign control of eight Arctic states, ${ }^{30}$ and sovereignty disputes are limited to predictable squabbles over maritime boundaries between states or the extent of a continental shelf claim, disputes which are examined by Ted McDorman and Clive Schofield in Chapter 7 of this volume. In the Antarctic, on the other hand, the sovereign claims of the seven so-called claimant states are not generally recognized, and the ATS is premised on the Antarctic being a de facto international space or at the very least, a space where traditional notions of sovereignty do not apply. Shirley Scott goes as far as to ask whether sovereignty has developed a 'unique meaning' in the Antarctic context in Chapter 8 of this Research Handbook.

25 Ibid.

26 GRID-Arendal, 'Boundaries of the Arctic Council Working Groups' at https:/grid-arendal .herokuapp.com/resources/8387 (accessed 14 April 2020).

27 Arctic Monitoring and Assessment Programme (AMAP), AMAP Assessment Report: Arctic Pollution Issues (AMAP, Oslo, 1998), 9-10.

28 GRID-Arendal, note 26; H Meltofte (ed), Arctic Biodiversity Assessment: Status and Trends in Arctic Biodiversity, Synthesis (Conservation of Arctic Flora and Fauna, Akureyri, 2013), 14-16.

${ }_{29}$ Heike Deggim, 'The International Code for Ships Operating in Polar Waters (Polar Code)' in Lawrence P Hildebrand, Lawson W Brigham and Tafsir M Johansson (eds), Sustainable Shipping in a Changing Arctic (Springer, Cham, 2018), 15, 29-30.

30 Canada, Kingdom of Denmark (Greenland and the Faroe Islands), Finland, Iceland, Norway, Sweden, Russia and the United States. 


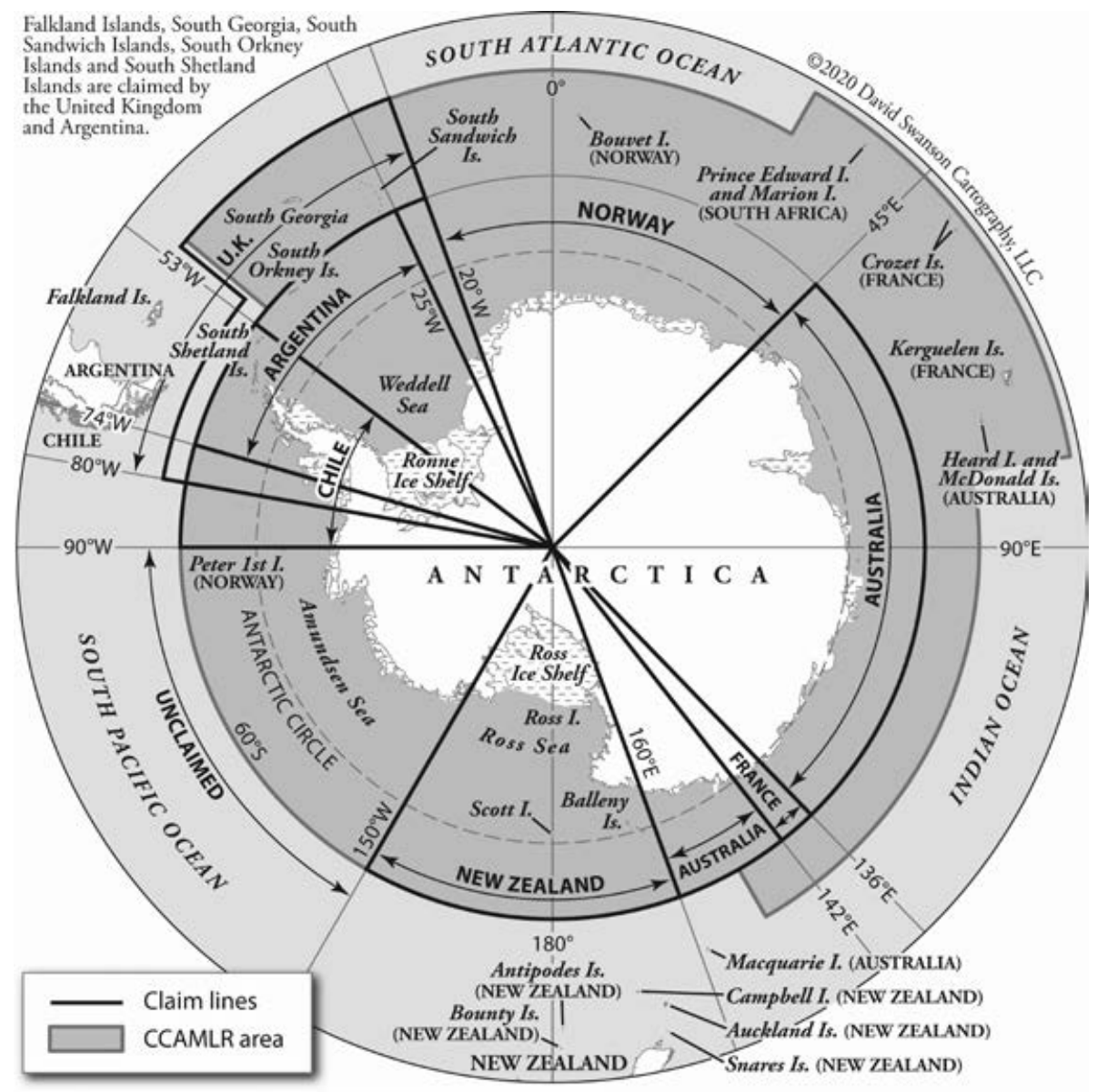

Note: $\quad$ (C) David Swanson Cartography LLC.

Sources: CCAMLR, 2013; Oxford Handbook on the Law of the Sea, 2013.

\section{Map 1.1 Map of the Antarctic}

On the other hand, there are undoubted similarities between the Poles. Ice is still a dominating presence in both the Arctic and the Antarctic and, through the medium of climate change, directly links the regional to the global through its contribution to sea level rise and alterations in ocean chemistry. The Poles have been warming by more than double the global average over the last two decades ${ }^{31}$ and so-called feedback loops, particularly in the Arctic, including a reduced albedo effect owing to a loss of sea ice and the release of methane from melting

31 MM Meredith, S Sommerkorn, C Cassotta et al., '2019: Polar regions' in H O Pörtner, DC Roberts, V Masson-Delmotte et al. (eds), IPCC Special Report on the Ocean and Cryosphere in a Changing Climate (2019, in press), 205. 


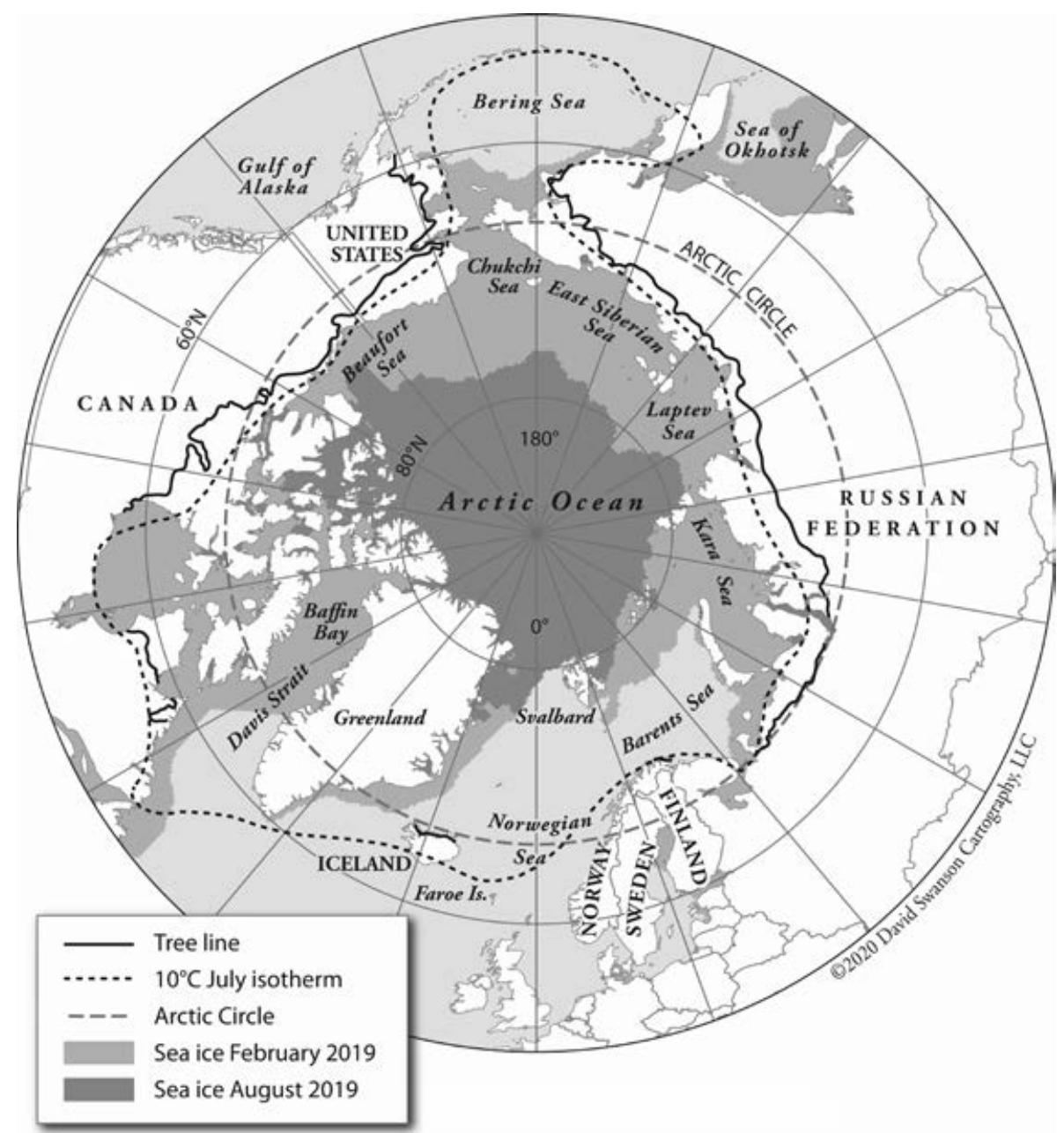

Sources: CAVM team, 2003; Stonehouse, 1989; National Snow \& Ice Data Center Sea Ice Index.

\section{Map $1.2 \quad$ Map of the Arctic}

permafrost, are actively contributing to global climate change. ${ }^{32}$ The particular vulnerability of the Poles to climate change and ocean acidification connects them in a way that is unique in a global context, and this is explored by Colin Summerhayes, Jan Zalasiezicz, Davor Vidas and Mark Williams in Chapter 2 on Poles and the Anthropocene and by Rosemary Rayfuse and Tim Stephens in Chapters 20 and 21 on climate change and ocean acidification respectively. The Poles constitute a 'sink' for many sources of chemical pollution and, as explored by Sabaa Khan and Seita Rompannen in Chapter 19 of this volume, are similarly vulnerable to pollution owing to continuously low temperatures, limited light, fresh water and localized

32 Ibid. 
nutrients and similar endemic bacterial communities vulnerable to microbial invasion. This unique vulnerability across both regions has led to the development of environmental protection as a core focus of governance in both the Arctic and the Antarctic, a theme explored by Robin Warner in Chapter 16 of this Research Handbook.

As noted above, both Poles have provided inspiration for innovative governance arrangements. Although very different in nature and scope, institutions and regimes in both the Arctic and the Antarctic have deliberately departed from a straightforward application of traditional state sovereign control. The 1920 Svalbard Treaty, Arctic Council and the ATS all respondto varying degrees - to the idea of the Poles as more than 'regional' and, in the case of the Antarctic, as part of the 'global commons'. This is most clearly demonstrated by the interest and active roles taken within Polar regimes by states and organizations that are not 'regional' in the traditional sense and this theme, with a focus on China and the European Union, is explored by Nengye Liu in Chapter 9 of this volume.

In crude terms, the question for this Research Handbook is whether the commonalities between the Poles transcend their very real differences in order to provide a foundation for the development of a coherent and principled body of law that applies across and to both Poles.

\section{IS THERE A DISTINCT BODY OF RULES APPLICABLE TO THE POLAR REGIONS?}

Polar Law as a distinct set of rules, principles and soft obligations that applies to the Polar regions can be divided into three main categories: law developed for both Poles; law developed for the Arctic and for the Antarctic at both the regional and the domestic level; and international law that has been adapted to apply to the Poles.

Thus far, there is little law that has been specifically developed to apply to both Polar regions. The International Maritime Organization (IMO) Polar Code, which establishes standards and protocols for ships operating in the Arctic and the Antarctic, and discussed by Kirstin Bartenstein and Aldo Chircop in Chapter 19 of the volume, is a notable exception. Precursors to the Code were Guidelines for Ships Operating in Arctic Ice Covered Waters issued in 2002, which were revised in 2009 to extend to both Arctic and Antarctic waters through Guidelines for Ships Operating in Polar Waters. ${ }^{33}$ In 2010, the IMO agreed to a proposal from several member states to develop an internationally binding instrument for polar shipping and, following adoption of safety measures by the Maritime Safety Committee in 2014, the pollution prevention measures by the Marine Environment Protection Committee in 2015, and associated amendments to the SOLAS and MARPOL Conventions, the Polar Code entered into force on 1 January $2017 .{ }^{34}$

In a rare example of Polar regional cooperation, the Arctic Council and the Antarctic Treaty Consultative Meeting (ATCM) issued a Joint Declaration on the International Polar Year and Polar Science in 2009, urging researchers to continue to cooperate in Polar science and to disseminate their research findings, as well as urging states to deliver a lasting legacy

33 Deggim, note 29, 18.

34 Ibid, 19. 
from the International Polar Year. ${ }^{35}$ More generally, however, there has been no collaboration between the Arctic Council and the ATCM on common issues such as climate change and ocean acidification.

The most important category of Polar Law is the law that has been developed for the Arctic and for the Antarctic through regional regimes.

The Antarctic Treaty System, comprising the 1959 Antarctic Treaty, 1991 Madrid Protocol, 1980 CAMLR Convention as well as the dormant 1972 Convention for the Conservation of Antarctic Seals (CCAS), the defunct 1988 Convention for the Regulation of Antarctic Mineral Resource Activities (CRAMRA) and more than 200 measures, resolutions and decisions is subject to detailed examination by Jill Barrett in Chapter 3 of this Research Handbook. The ATS is intended to be relatively comprehensive and regulates all activities in the Antarctic (other than shipping), including scientific research (explored by Paul Berkman in Chapter 6), tourism (the focus of Chapter 15 by Daniela Liggett and Emma Stewart), fishing (Chapter 10, by Marcus Haward), minerals exploration (Chapter 13, by Rachael Johnstone and Scott Joblin) and area-based protection (Chapter 17, by Suzanne Lalonde). The ATS is founded on a set of clearly articulated principles that prioritize peaceful purposes, cooperation, scientific research and strict environmental protection. These principles have shaped the evolution of the ATS over the last 60 years as it has expanded its remit in order to address fisheries management, minerals exploitation and other activities not directly addressed by the Antarctic Treaty. While demonstrating undoubted internal coherency in terms of its application to the Antarctic, initiatives can, however, be undermined by tension between these principles and the sovereignty compromise, brokered by Article IV of the Antarctic Treaty, whereby states with and without claims are able to participate in the ATS without prejudice to their position on the sovereign status of Antarctica. For example, the coincidence between states asserting sovereign claims and states proposing large marine protected areas (MPAs) has hindered the process of developing a network of MPAs in the Antarctic under the CAMLR Convention. ${ }^{36}$ The desire to avoid engaging in a discussion relating to access to and sharing the benefits of Antarctic genetic resources has led to a very limited regulation of bioprospecting activities in the Antarctic, essentially confined to its environmental impacts, as discussed by David Leary in Chapter 14 of this Research Handbook. Nevertheless, the 'Antarctic' component of Polar Law is significant in terms of scope, impact and effectiveness.

By contrast, the 'Arctic Council System', to use Molenaar's term, is, in the words of Timo Koivurova, Pirjo Kleemola-Juntunen and Stefan Kirchner in Chapter 4 of this volume, 'an emerging set of norms'. Originally a much looser arrangement of institutions largely based on cooperative research and monitoring programmes with an environmental focus, ${ }^{37}$ the Arctic Council now plays an important coordinating role and, under its auspices, three binding instru-

35 Antarctic Treaty - Arctic Council Joint Meeting, Washington Ministerial Declaration on the International Polar Year and Polar Science (adopted 6 April 2009), reproduced in Final Report of the Thirty-second Antarctic Treaty Consultative Meeting (Baltimore, United States, 6-17 April 2009), Annex 2.

36 See Cassandra M Brooks, 'Competing Values on the Antarctic High Seas: CCAMLR and the Challenge of Marine Protected Areas' (2013) 3 The Polar Journal 277.

37 Including the Arctic Contaminants Action Program (ACAP), the Arctic Monitoring and Assessment Programme (AMAP), Conservation of Arctic Flora and Fauna (CAFF), Emergency Prevention, Preparedness and Response (EPPR), Protection of the Antarctic Marine Environment (PAME) and the Sustainable Development Working Group. 
ments have been adopted. ${ }^{38}$ But the Arctic Council has a very limited regulatory mandate and, as a consequence, Arctic governance comprises a much broader range of instruments at both the domestic as well as the regional level. This is illustrated in particular by the regulation of tourism as discussed by Daniela Liggett and Emma Stewart in Chapter 15, bioprospecting (David Leary, Chapter 14) and marine protected areas (Suzanne Lalonde, Chapter 17). In contrast to the Antarctic, there is no overarching fisheries management organization for the Arctic. Rather, as discussed by Alf Håkon Hoel in Chapter 11, fisheries are regulated through a patchwork of regional, sub-regional and bilateral arrangements. However, in 2018, the 'Arctic Council System' was augmented by an important but institutionally distinct instrument formalizing a moratorium on fishing in the Central Arctic Ocean. ${ }^{39}$ This instrument is significant in that it is based on existing and emerging Arctic values. Like the Arctic Council itself, the CAOFA acknowledges international interests in the region, but it went beyond the practice of the Council in actually permitting non-Arctic states, including China, South Korea, Japan and the European Union, to engage directly in its negotiation. These states have signed the Agreement and will become full parties once it enters into force. Moreover, Arctic Indigenous peoples are recognized in the Agreement, which recalls the 2007 United Nations Declaration on the Rights of Indigenous Peoples in its preamble, and institutionalizes the involvement of Indigenous peoples in its Joint Program of Scientific Research and Monitoring. ${ }^{40}$ The focus of the CAOFA is strongly environmental in that it introduces a highly precautionary (but time limited) moratorium on commercial fishing in the Central Arctic Ocean in anticipation of those waters becoming more accessible in the future owing to climate change. So, while the Arctic lacks the internal coherency of the ATS at this stage, there is little doubt that Arctic regime-building has developed rapidly over the last decade and a body of 'Arctic Law' is readily identifiable.

The third category within the corpus of Polar Law is the more general rules and principles of international law that have been adapted for particular application at the Poles. International shipping law provides the best example of this category. For example, Article 234 of the 1982 United Nations Convention on the Law of the Sea (UNCLOS) ${ }^{41}$ permits coastal states the right to adopt and enforce non-discriminatory laws and regulations for the prevention, reduction and control of marine pollution from vessels in ice-covered areas within their exclusive economic zones (EEZs). In Chapter 18, Kirstin Bartenstein and Aldo Chircop discuss how MARPOL 73/78 has designated the Antarctic Treaty area as a MARPOL Special Area within which the discharge of oil, noxious liquid substances and garbage is more tightly regulated and the carriage of heavy fuel oil (HFO) as cargo or fuel is banned. ${ }^{42}$ They engage with the question of whether 'Polar shipping law' can be said to exist as a discrete discipline, but caution that

38 Agreement on Cooperation on Aeronautical and Maritime Search and Rescue in the Arctic, adopted 12 May 2011, entered into force 19 January 2013, (2011) 50 ILM 1119; Agreement on Cooperation on Marine Oil Pollution Preparedness and Response in the Arctic, adopted 15 May 2013, entered into force 25 March 2016, CTS 2013/6; Agreement on Enhancing International Arctic Scientific Cooperation, adopted 11 May 2017, entered into force 23 May 2018 at https://oaarchive.arctic-council .org/handle/11374/1916 (accessed 9 November 2019).

39 CAOFA, note 16.

40 Ibid, Art 4(4).

41 Adopted 10 December 1982, entered into force 16 November 1994, 1833 UNTS 397.

42 Addition of a new Chapter 9 to MARPOL, Annex 1, IMO Resolution MEPC.189(60), 26 March 2010; MARPOL, Annex I, Chapter 9, Regulation 43(1). 
the term may 'create a false impression that there is a homogenous and distinct body of law'. It is notable that the adaptation of global shipping law has thus far largely occurred in favour of the Antarctic rather than both Poles. There are no MARPOL Special Areas in the Arctic, for example, although the Polar Code does impose similar discharge restrictions to Arctic waters. An Antarctic-style HFO ban has been under consideration in the IMO for some time but has yet to be adopted. ${ }^{43}$

Environmental principles constitute another area where international law has been adapted to the Polar context, as explored by Robin Warner in Chapter 16 and, in the specific contexts of marine mammal conservation by Richard Caddell in Chapter 12 and area-based management by Suzanne Lalonde in Chapter 17. The application of a robust version of the precautionary approach in the context of climate change is undoubtedly emerging as a Polar adaptation. The CAOFA is the first instrument to introduce a preemptive ban on fishing on the high seas in order to protect ecosystems newly accessible owing to climate change. In the Antarctic, precaution has a much longer lineage, being introduced - albeit not initially implemented - in the CAMLR Convention in 1980 and underpinning the entire approach of the Madrid Protocol. This is demonstrated explicitly in the Protocol's stringent provisions relating to environmental impact assessment, which require a full comprehensive evaluation of any project likely to have 'more than a minor or transitory impact' on the environment. ${ }^{44}$ Although the ATCM has been less vocal and proactive in relation to climate change in comparison to the Arctic Council, the adoption, by the Commission for the Conservation of Antarctic Marine Living Resources (CCAMLR), of a conservation measure in 2016, ${ }^{45}$ allowing for the special protection of Antarctic Peninsula areas newly exposed by ice retreat, also constitutes a highly precautionary measure in the face of climate change.

So 'Polar Law' in the sense of an identifiable and discrete set of principles and obligations that apply to either or both Poles undoubtedly exists. Polar Law is sufficiently distinctive that it can be distinguished from other regional law and from the application of international law more generally, although international law applies to the Poles to the extent that it is not displaced by the lex specialis of Polar Law as it does to any other region. As demonstrated by all chapters in this Research Handbook, Polar Law as a body of discrete rules has developed in scope, depth and sophistication over the last 50 years or so and arguably has many lessons for other regions and for the international community more generally.

\section{IS 'POLAR LAW' A BODY OF RULES BASED ON A COHERENT SET OF PRINCIPLES AND VALUES?}

Beyond its undeniable existence as a distinctive set of principles and rules that apply to the Poles, can 'Polar Law' be described as an internally coherent body of law underpinned by

43 The carriage of heavy fuel oil as cargo and fuel was prohibited in the territorial sea areas of Svalbard's national parks and nature reserves in 2015 by virtue of the 2001 Svalbard Environmental Protection Act.

44 Madrid Protocol, Art 8 and Annex 1.

45 CCAMLR, CM 24-04 (2017) Establishing time-limited Special Areas for Scientific Study in newly exposed marine areas following ice-shelf retreat of collapse in Statistical Subareas 48.1, 48.5 and 88.3 (originally adopted in 2016). 
identifiable values and principles that apply consistently and uniquely to both Poles? Can we predict how Polar Law will develop in the future on the basis of its values and principles? Can we identify a 'Polar' response to issues such as climate change, pollution and conservation of endangered species on the basis of shared principles and values? This is a much more challenging exercise. Identifying bipolar (Antarctic and Arctic) principles and values is not the same as recognizing those as Polar principles and values. Nevertheless, the chapters in this Research Handbook reveal commonality across at least five principles that arguably provide the basis for an emerging body of Polar Law: cooperative internationalized governance; peaceful purposes; freedom and cooperation in scientific research; protection of the Polar environment; and precautionary action in the context of climate change.

First, cooperative internationalized governance describes the strong values of cooperation and internationalization in Polar governance institutions and instruments. The degree of both cooperation and internationalization obviously differs between the Arctic and the Antarctic, but both regions are nevertheless characterized by deep international cooperation based on rules. The ATS is a wholly cooperative international arrangement and, whilst Antarctica is not formally part of the global commons - seven states maintain sovereign claims to the continent-Antarctica is managed as a de facto international space. Most of the Arctic is, by contrast, subject to the sovereign jurisdiction of nation states. However, that sovereignty is moderated to a limited degree by the cooperative arrangements entered into by Arctic states as part of the Arctic Council System. The Arctic Council itself has departed from a typical regional arrangement in that six Indigenous peoples groups have the status of Permanent Participants and, in practice, participate on nearly an equal basis to state members and that 13 non-Arctic states have been formally approved as observers to the Council. The most recent Arctic instrument to be adopted, the CAOFA, was negotiated by both Arctic and non-Arctic states, as well as Arctic Indigenous peoples, although the Agreement recognizes the special rights and responsibilities of the Arctic littoral states. The connection between Arctic peoples across traditional state boundaries is arguably stronger in the Arctic than in any other region, and the importance of the Arctic as a trade route for shipping elevates the regional to the international. Moreover, as noted above, both Poles are connected to the international and the global through their vulnerability to climate change and contribution to its impacts, in particular, through sea level rise. All states therefore have an interest in Polar governance and this is reflected, albeit very differently, in Antarctic and Arctic governance arrangements.

The second principle or value is peaceful purposes. This is enshrined in Article I of the Antarctic Treaty, which created Antarctica as the first international demilitarized space. Peaceful purposes underpins all Antarctic instruments and, while its scope may come under occasional challenge from enforcement activities and dual purpose research for example, its status as a core Antarctic principle and value has never been disputed. By contrast, the 1996 Ottawa Declaration on the Establishment of the Arctic Council ${ }^{46}$ makes no reference to 'peaceful purposes' in the context of the Arctic. Nevertheless, this principle arguably underpins Arctic governance with Oran Young, deriving inspiration from Mikhail Gorbachev's 1987 Murmansk speech on the future of the Far North, describing the Arctic as a 'zone of peace'. ${ }^{47}$ However, while various Arctic Council ministerial declarations have reaffirmed the commit-

46 Ottawa Declaration, note 13.

47 Oran R Young, 'The evolution of Arctic Ocean governance: Challenges and opportunities' in Oran R Young, Jong Deog Kim and Yoon Hyung Kim (eds), The Arctic in World Affairs: A North 
ment to maintain peace, stability and constructive cooperation in the Arctic, ${ }^{48}$ large capital expenditures have been incurred by many Arctic states on military and coast guard assets. ${ }^{49}$ Such expenditures might be explained as being required for constabulary roles in environmental and resource protection, but concerns continue over whether militaries are being given new equipment that goes beyond protecting fish stocks or other natural resources. ${ }^{50}$

The third principle relates to freedom of and cooperation in scientific research. Article II of the Antarctic Treaty preserves the freedom of scientific investigation, while Article III prioritizes research collaboration and the free dissemination of research. Scientific research has remained the preeminent activity in Antarctica and is given priority over other activities under the Madrid Protocol ${ }^{51}$ and operates as the 'currency' for participation in Antarctic governance. ${ }^{52}$ Research and monitoring of the vulnerable Arctic ecosystem is the primary form of cooperation and collaboration in the region, and the Arctic Council was built on the foundation of the four research and monitoring programmes in existence in 1996 (AMAP, CAFF, Protection of the Arctic Marine Environment (PAME) and Emergency Prevention, Preparedness and Response). The most recently adopted treaty under the auspices of the Arctic Council, the 2017 Agreement on Enhancing International Arctic Scientific Cooperation, ${ }^{53}$ derives significant inspiration from the Antarctic Treaty. It requires parties to use best efforts to facilitate the entry and exit of scientists and equipment from their territory ${ }^{54}$ and to facilitate access to civilian research facilities and logistical services as well as to their territory more generally for research purposes. ${ }^{55}$ Furthermore, the Agreement encourages parties to support full and open access of scientific metadata and to encourage open access of data products and published results. ${ }^{56}$ While the 2017 Agreement does not guarantee an absolute freedom of scientific research, which is unsurprising given that it is designed to apply within as well as beyond the territory of states, it nevertheless complements the Antarctic Treaty and, collectively, these instruments have undeniably developed a Polar approach to scientific research within the region.

The penultimate principle or value, which might also be described as an overarching objective of both regimes, is environmental protection. Although not expressly articulated in the Antarctic Treaty, strict environmental protection underpins the broader Antarctic Treaty

Pacific Dialogue on the Future of the Arctic, 2013 North Pacific Arctic Conference Proceedings (Korea Maritime Institute/East-West Center, Seoul/Honolulu), 267, 267.

48 See, e.g., the Nuuk Declaration (12 May 2011), the Kiruna Declaration (15 May 2013), the Iqaluit Declaration (24 April 2015), and the Fairbanks Declaration (11 May 2017), all at https://arctic-council .org/en/resources (accessed 22 April 2020).

49 Rob Huebert, 'Rising temperatures, rising tensions: Power politics and regime building in the Arctic' in Stephens and VanderZwaag, note 4, 65, 66.

s0 Ibid, 66-67.

51 See, e.g., Madrid Protocol, Art 3(1).

52 R Herr and R Hall, 'Science as currency and the currency of science' in J Handmer (ed), Antarctica: Policies and Policy Development (Centre for Resource and Environmental Studies, Australia National University, Canberra, 1989); Karen N Scott, 'Scientific rhetoric and Antarctic security' in Alan D Hemmings, Donald R Rothwell and Karen N Scott (eds), Antarctic Security in the Twenty-First Century: Legal and Policy Perspectives (Routledge, London, 2012), 284.

53 See note 38.

$54 \quad$ Ibid, Art 4.

55 Ibid, Arts 5 and 6.

56 Ibid, Art 7. 
System. The Madrid Protocol establishes some of the strictest environmental controls of any region on activities ranging from scientific research to tourism to infrastructure development. The CAMLR Convention operates as the regional fisheries organization (RFMO) for the Southern Ocean, but is far from a typical RFMO and has been described as 'fundamentally a conservation instrument with some of its provisions related to regulating fishing activities, rather than a fisheries management agreement that has conservation provisions' ${ }^{57}$ The ATS has demonstrated strong global environmental leadership, including, under the auspices of CCAMLR, designating the first ${ }^{58}$ and then the largest high seas marine protected area ${ }^{59}$ In the Arctic, environmental standards differ between jurisdictions, and the balance between environmental protection and (sustainable) development is more complex. Moreover, in contrast to the Antarctic, there are few binding environmental standards that apply across the Arctic. Nevertheless, environmental cooperation is a core feature of Arctic governance, and the Arctic Council was deliberately established as a high level forum to provide a means of cooperation, coordination and interaction among Arctic states and Indigenous communities on issues of sustainable development and environmental protection in the Arctic. ${ }^{60}$ The pollution prevention and control efforts, especially of the Arctic Council's PAME and Arctic Contaminants Action Program (ACAP) Working Groups, have been well documented elsewhere ${ }^{61}$ and are explored in various chapters in this Research Handbook. Thus, environmental protection is undoubtedly a Polar principle or value that applies across both regions.

The final principle, which could also be described as an emerging Polar policy, is precaution in response to climate change. The precautionary approach or principle is obviously not uniquely Polar in origin but, in the particular context of climate change, its application across both Poles is distinctively robust. As noted above, both the Arctic and the Antarctic regimes have responded to the very particular threat that climate change poses to both regions by adopting highly precautionary action to protect fisheries that become exposed - and thus accessible - as a consequence of ice loss. In the Arctic, the CAOFA, adopted in 2018, establishes a 16-year de facto moratorium on fishing in the Central Arctic Ocean, with significant obligations around research and monitoring designed to underpin decision-making once the Agreement becomes operational. ${ }^{62}$ In the Antarctic, strict protection of the vulnerable and largely untouched Ross Sea in response to climate change, as well as other threats, was a primary motivation for the establishment of the Ross Sea MPA. ${ }^{63}$ Moreover, areas newly exposed as a consequence of ice loss may be designated Special Areas for Scientific Study

57 Anthony J Press, Indi Hodgson-Johnston and Andrew J Constable, 'The principles of the Convention on the Conservation of Antarctic Marine Living Resources: Why its Commission is not a Regional Fisheries Management Organisation' in Liu, Brooks and Qin, note 4, 9.

58 CCAMLR CM 91-03 (2009) Protection of the South Orkney Islands Southern Shelf.

59 CCAMLR CM 91-05 (2016) Ross Sea region marine protected area.

60 Ottawa Declaration, Art 1(a).

${ }_{61}$ See, e.g., Jim Gamble, 'Arctic Council responses to land-based and air pollution' in Robert W Corell, Jong Deog Kim, Yoon Hyung Kim, Arild Moe, Charles E Morrison, David L VanderZwaag and Oran R Young (eds), The Arctic in World Affairs: A North Pacific Dialogue on Global-Arctic Interactions: The Arctic Moves from Periphery to Center, 2019 North Pacific Arctic Conference Proceedings (Korea Maritime Institute/ East-West Center, Seoul/Honolulu, 2019), 322.

${ }^{62}$ See Rosemary Rayfuse, 'The Role of Law in the Regulation of Fishing Activities in the Central Arctic Ocean' (2019) 110 Marine Policy 103562; David L VanderZwaag, 'Governance of fisheries in the Central Arctic Ocean: Cooperative currents, foggy future' in Liu, Brooks and Qin, note 4, 92.

63 CM 91-05, note 59, para 3(2). 
for up to ten years and subject to significant restrictions on fishing by CCAMLR, ${ }^{64}$ and two such areas have already been established. ${ }^{65}$ Although it would be premature to argue that a robust application of the precautionary approach applies in the Arctic to the same extent as the Antarctic, a 'Polar' version of the precautionary principle is nevertheless clearly emerging in the very particular context of Polar fisheries management in response to climate change, especially ice loss.

It is not argued here that there is currently a unified body of law that applies to both Poles in the way that European law applies within the European Union, for example. Nor is it argued that the principles and values identified here are identical in scope or definition across the Poles. Moreover, there are obviously areas and activities that are managed very differently in the Arctic compared to the Antarctic, in respect of which there is no Polar approach as such. The rules around minerals exploitation, bioprospecting and even area-based protection, for example, are 'Poles apart' to use David Leary's phrase in Chapter 14 of this Research Handbook. Nevertheless, the core principles or values identified in this section do apply across the Poles in a way that is distinctly Polar. As such, they clearly provide at least a basis for a body of law that can be authentically and realistically described as 'Polar Law'. They can be used as a foundation for developing new Polar norms and thus we can reasonably predict that Polar Law will develop on the basis of and within the parameters of these principles and values. We can also point to a Polar response to some common issues such as climate change and the modalities of carrying out scientific research in the region. In conclusion, Polar Law exists not only as distinct rules, principles and soft obligations that apply to the Poles, but also as an emerging internally coherent body law based on shared principles and values that are undeniably Polar in origin, content and application.

\section{DO WE NEED 'POLAR LAW'?}

A not unreasonable challenge to a project on Polar Law is the question of whether and why we need a body of law that applies in an internally coherent and principled way to both the Arctic and the Antarctic. What value is added by Polar Law to the existing regimes in the Arctic and the Antarctic or by reimagining those separate regional regimes as part of an overarching Polar normative framework? Furthermore, does such an exercise risk undermining rules and principles that have been developed to operate in the very particular Arctic and, especially, Antarctic geopolitical and environmental conditions? These are important questions that are not intended to be answered in this Research Handbook, but which naturally follow from its stated objective: the ascertainment and identification of Polar Law.

A preliminary assessment, however, would suggest that Polar Law does add value to our existing bipolar normative frameworks and to international law more generally. The principles and values set out in the previous section that underpin Polar Law arguably serve to strengthen their application within the Arctic and the Antarctic by virtue of their status as Polar Law.

4 CM 24-04, note 45.

65 In 2017 the Larsen C Special Area for Scientific Study (SSAS) was designated for 10 years as a Stage 2 SASS (CM 24-04, note 45, Annex B), and in 2019 the marine area adjacent to the Pine Island Glacier was designated a State 1 SASS for two years (see Report of the Thirty-eighth Meeting of the Commission, Hobart, Australia, 21 October to 1 November 2019, [6.6-6.14]). 
Whilst a wholesale transposition of rules and principles from one Pole to the other would be clearly inappropriate, there is no doubt that lessons can be learned from both regions, improving the content, application and enforcement of Polar norms. The principles of freedom of and cooperation in scientific research for example, provide a contemporary illustration of the Arctic learning from Antarctic practice. Furthermore, entrenching these principles and values at the Poles also has lessons for international law more generally. Polar governance that departs (to varying extents) from traditional state sovereignty, is relatively inclusive and that has developed unique approaches to managing disputes over territory and resources provides models for other regions or, at the very least, demonstrates that alternative models to traditional state-based control can be developed where there is political will.

Moreover, a strong argument can be made that Polar Law is needed in the face of similar threats to the Polar region, not least from climate change. A 'Polar' response, representing the interests of more than 50 nations to climate change or pollution or ecosystem-based management inevitably carries more weight than a response developed by the Arctic or the Antarctic separately. Given the varying degree of success that traditional international law has, and indeed is having, in addressing global problems such as climate change, environmental degradation, and disagreements over resource exploitation, the Polar model of governance is arguably more necessary than ever. If we accept that traditional normative frameworks are limited in the face of rapidly changing political and, more importantly, environmental conditions, a model that is clearly open to experimenting with and departing from those traditional frameworks perhaps provides us with one example of normative governance that is capable of responding to the new 'Anthropocene'.

Finally, developing Polar Law as a distinct discipline need not undermine the specific rules that apply within the Arctic and the Antarctic. Polar Law, as articulated above, is based on overarching principles and values. It does not seek to homogenize the particular rules that apply to the Poles in respect of environmental impact assessment or the exploitation of mineral resources, for example. It recognizes that internationalized governance is implemented in contextually distinct ways and does not call for the replication of the Antarctic Treaty System in the Arctic. ${ }^{66}$

\section{WHAT ARE THE CHALLENGES TO POLAR LAW?}

Finally, this Research Handbook explores the challenges to Polar Law. Challenges may be both internal and external to the Polar regime. For example, as global political dynamics change and states that were not engaged in the early stages of Polar Law development seek to engage, actively participate and, ultimately, influence the future direction of Polar Law, will this have implications for Polar Law's foundational values and principles? Institutional challenge by states such as China within the ATS has received significant attention in the academic literature ${ }^{67}$ and the role of the European Union in the Arctic has also come under particular 4497.

${ }^{66}$ See, e.g., Oran R Young, 'Is It Time for a Reset in Arctic Governance?' (2019) 11 Sustainability

67 See, e.g., Anne-Marie Brady, China as a Polar Great Power (Woodrow Wilson Center Press and Cambridge University Press, Cambridge, 2017). 
scrutiny. ${ }^{68}$ This theme is picked up in a number of chapters in this Research Handbook and is addressed in detail by Nengye Liu in particular, in Chapter 9. Just as the engagement of states from outside of the Poles represents a challenge for Polar Law, the disengagement of states is arguably equally challenging. The most significant threats to the Poles, such as climate change and chemical pollution, originate from outside the Polar regions and cannot be addressed by Polar Law alone. As Sabaa Khan and Seita Rompannen argue in Chapter 19 of this volume, 'ambitious [Polar] ecosystem protection objectives are counteracted by weak international regulation of hazardous chemicals and waste'. While shipping law has benefited from a strong Polar dimension, ultimately, comprehensive regulation is developed at the international level by the IMO and, as explored by Kirstin Bartenstein and Aldo Chircop in Chapter 18 of this Research Handbook, 'Polar Shipping Law' requires a sophisticated integration of domestic, regional and international rules. Rosemary Rayfuse and Tim Stephens draw similar conclusions with respect to the threats posed by climate change and ocean acidification to the region.

The most significant challenge to Polar Law, however, is that Polar Law, like international law more generally, relies, in the words of Colin Summerhayes, Jan Zalasiezicz, Davor Vidas and Mark Williams in Chapter 2 of this volume, on the stable environmental conditions that characterized the late Holocene. By contrast, the Anthropocene is likely to be disrupted by significant environmental and social change, and the challenge for Polar Law will be responding to this change and adapting to the Anthropocene. Notwithstanding the 'experimental' nature of much Polar governance, to date, it nonetheless remains subject to the structural constraints of international law more generally. Ultimately, the question is whether Polar Law is uniquely positioned to move beyond these structural constraints, leveraging its distinctive principles and values in order to effectively respond to and engage with the Age of the Anthropocene.

\section{CONCLUDING REMARKS}

We conclude this introduction with two observations. First, whether Polar Law is defined as the collective of rules and principles that applies to the Poles or a coherent body of law underpinned by distinctive Polar principles and values, it has undeniably emerged as a distinctive field of research. The 21 chapters in this volume attest to that reality. Second, Polar Law is not static but dynamic. Social, economic, ecological and political pressures will continue to drive the evolution of the law and principles applicable to the Antarctic and Arctic. This Research Handbook can only provide a 'present take' of the legal developments and challenges facing the Poles. From a long-term perspective, Polar Law research has hardly begun.

68 See, e.g., Kristine Offerdal, 'The EU in the Arctic: In Pursuit of Legitimacy and Influence' (2011) 66 International Journal 861. 